\title{
Metacognitive Skills Analysis of Students with High Mathematics Ability to Solve the Problems of Polya Based Mathematical Stories
}

\author{
Sunyoto Hadi Prayitno \\ \{nyoto_hp@unipasby.ac.id \\ Mathematics Education, University of PGRI Adi Buana Surabaya
}

\begin{abstract}
This qualitative research aims to describe the metacognitive skills of highly capable students in solving Polya-based mathematical story problems. The subject in this study was 1 student with high mathematical abilities based on a math ability test. The research data was obtained from math test questions and interviews. The data analysis uses indicators of metacognitive skills, which are planning, monitoring and assessment. Each indicator of metacognitive skills is connected with Polya-based problem solving steps, which are understanding the problem, planning a solution, implementing a settlement plan, and re-checking the settlement. The results showed that metacognitive skills of students with high mathematics ability to solve problems appeared in every step of solving Polyabased mathematical story problems in detail.
\end{abstract}

Keywords: Metacognitive skills, story matter, Polya problem solving

\section{Introduction}

Mathematics as one of the subjects in school is considered to have an important role in shaping students to be qualified, because mathematics is a means of thinking to examine things logically and systematically [1]. Therefore, in learning mathematics in schools must be tried a lot of practice solving problems. However, not all students are the same in dealing with problems [2]. There are students who feel challenged to immediately solve math problems, but not so with other students.

The formal problems can be defined as follows: "A problem is a situation, quantitative or otherwise, that confronts individual or group of individuals, that requires resolution, and for which the individual sees no apparent or obvius means or path to obtaining a solution. "This definition explains that a problem is a condition or situation faced by a person or group that needs a solution but does not have a way that can directly determine or resolve the solution [3].

In the simulation of the National Standardized School Examination (USBN) by the Surabaya Dispendik, the USBN subject that was considered most difficult by students was mathematics. Most math problems that are done are related to logic. In addition to having to think more carefully, students are required to work quickly because of limited time. This phenomenon must be followed up by introducing the problem and how to solve it correctly to students. Problems presented need to be linked to the reality faced by students, meaning that the problem is a contextual problem that is able to be solved with the help of experiences that students have [4]. 
The form of questions in mathematics in general can be divided into two, namely the matter of calculation and the question of the form of the story [5], problem to prove and problem to find [6]. The matter of the form of count is a matter that has been shaped by mathematical symbols. While the story problem is a mathematical problem that can be processed so that it shows a reasoning. In this research, story problems are used regarding straight line equations.

The problem solving requires the ability to evaluate the processes and results of thinking during problem solving [3]. Whereas Bailey states that problem solving is a complex activity and a high level of one's mental processes. Problem solving is defined as a combination of new ideas that prioritize reasoning as a basis for combining ideas and directing problem solving [7].

Regarding the importance of students' reasoning in solving mathematical problems, an example is needed in learning that emphasizes the steps in solving problems, one example is the problem solving steps from Polya. Steps for solving problems, among others understanding the problem, devising a plan, carrying out the plan and looking back [6], [8].

At the stage of understanding the problem, students try to determine what is asked, what data is known, what conditions are needed, what conditions have been met, whether the conditions are sufficient, drawing the model, and writing the appropriate symbols, and stating the problem with their own sentence. At the stage of making a completion plan, students determine the strategy to complete. Students recall whether they have ever known this problem before, had they ever seen the same problem but in a different form, then lowered the conditions or ways of resolution that could be used, then devised a solution. At the stage of implementing the completion plan, students carry out a settlement plan that has been made before, check every step taken, pay attention clearly that the step is correct, and prove that this is true. At the rechecking stage, students re-examine the truth of the answers obtained and the arguments used, trying to find different results using other methods.

In understanding problems, students need the knowledge stored in their memories to be used again, namely their metacongnif knowledge. Metacognitive knowledge is knowledge possessed by students and stored in long-term memory [9], [10]. This means that knowledge can be activated or recalled as a result of a memory melting that is done consciously intentionally, or activated accidentally / automatically arises when students are faced with certain problems [11].

The involvement of metacognitive aspects in the learning process is one aspect of the knowledge dimension that is important in regulating and controlling the cognitive processes carried out by students in learning and thinking, so that learning and thinking are done better, conducive, effective and provide a positive response so that a more effective learning strategy is needed to make students more active in the learning process.

Metacognition is classified into three components, namely (1) metacognition knowledge, (2) metacognitive experience, and (3) metacognitive skills [12]. Metacognition knowledge is defined as general knowledge about how one learns and processes information, such as one's knowledge of the learning process itself [13]. Metacognitive knowledge is categorized based on one's awareness of metacognitive knowledge, namely: procedural knowledge, and conditional knowledge [14]. Declarative knowledge, procedural knowledge, and conditional knowledge students need to have and realize to improve their metacognitive abilities [15], [16]. Declarative knowledge is factual knowledge that has been known to someone and can be expressed in words or writing. Procedural knowledge is the knowledge of how someone does something or how to do the stages of a process. Conditional knowledge is knowledge about when and why to use a strategy and when to use that strategy in learning.

Metacognitive experience contains the use of metacognitive strategies or metacognitive self-regulation (self-regulation metacognitive), which is the ability to use metacognitive 
knowledge strategically to achieve cognitive goals, especially in cases when one wants to overcome cognitive barriers. In the process of learning or problem solving, metacognitive selfregulation mentioned above is also commonly known as regulation [14].

Metacognitive experiences include the use of metacognitive or metacognitive strategies. Metacognitive strategies or metacognitive regulations are sequential processes that are used by someone to control their cognitive activity and ensure that their cognitive goals have been achieved. The process of controlling cognitive activity consists of planning, monitoring, and evaluating cognitive activity. The third process of controlling metacognitive activity is none other than metacognitive skills.

Planning activities (monitoring), monitoring (monitoring), and evaluation (evaluation) can also be referred to as metacognitive skills, namely the ability of students to control the cognitive skills of students, which consists of: planning skills, monitoring skills, and evaluation skills. Furthermore, it is explained that planning skills refer to the students' initial thinking activities about how, when, and why to carry out a series of actions to achieve the goal through a series of main objectives of the problem. Monitoring skills refer to the activities of student supervision of cognitive strategies that are used during the learning activities in progress, in order to recognize problems and modify plans. Accurate monitoring is important in the learning process. Evaluation skills are defined as backward verbalizations made by students after the event takes place, where students look back at the strategies that have been used and whether the strategy is directed at the results used or not [17].

The problem that arises in this study is "What are the students' metacognitive skills in solving Polya-based mathematical story problems?. The research objective to be achieved is to describe students' metacognitive skills in solving Polya-based mathematical story problems.

\section{Methods}

This research is a type of qualitative descriptive research. The research subjects were 1 student of Taman Sidoarjo State Junior High School I who had high mathematical abilities based on the results of a mathematical ability test. In this study, the grouping of mathematical abilities is used as a reference proposed by [18], as follows.

Table 1. Criteria for Grouping Students by Mathematical Capability

\begin{tabular}{lccc}
\hline Mathematical Ability & Low & Middle & High \\
\hline Math Ability Test Score & $0 \leq \mathrm{SM}<75$ & $75 \leq \mathrm{SM}<85$ & $85 \leq \mathrm{SM}<100$ \\
\hline
\end{tabular}

The researcher is the main instrument in this study, while the supporting instruments are math skills test questions, problem solving test questions, interview guidelines and audiovisual recording devices. The main instrument of the researchers themselves is because researchers will plan, implement and collect data.

Data collection techniques in this study are (1) Pre-survey, conducted to obtain research subjects of a student who has high mathematical abilities. The pre-survey is done by testing the math skills (2) Observation, conducted to find out the steps of students in solving Polya-based mathematical problems. (3) Interviews, used for students' metacognitive abilities in solving Polya-based mathematical problems. The data analysis techniques use the Flow Model which consists of Data Reduction, Data Presentation \& Credibility, Conclusion Withdrawal. 


\section{Research Result}

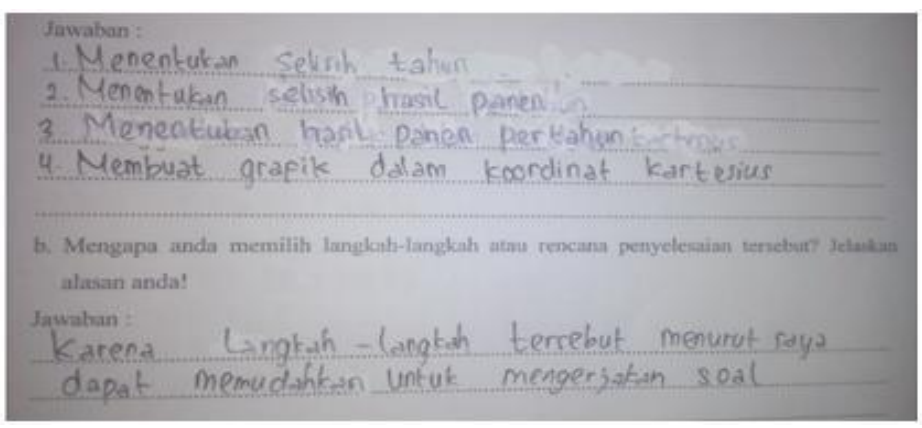

Fig 1. Work Results of Students in the Stage of Understanding the Problem

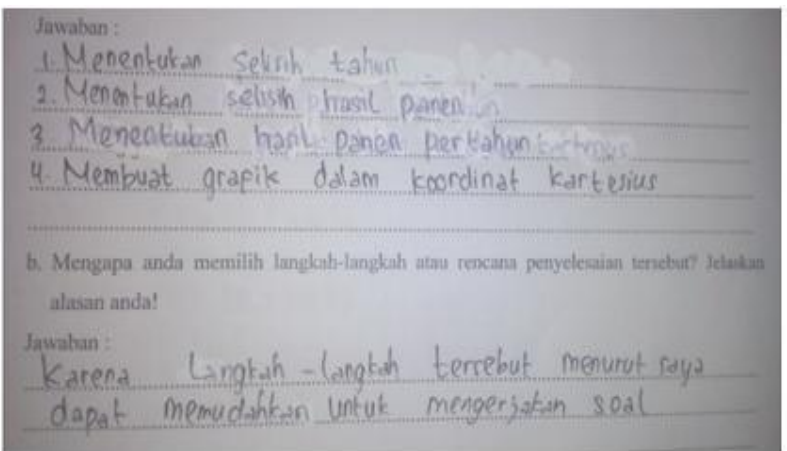

Fig. 2. Work Results of the Students Planning the Settlement Phase
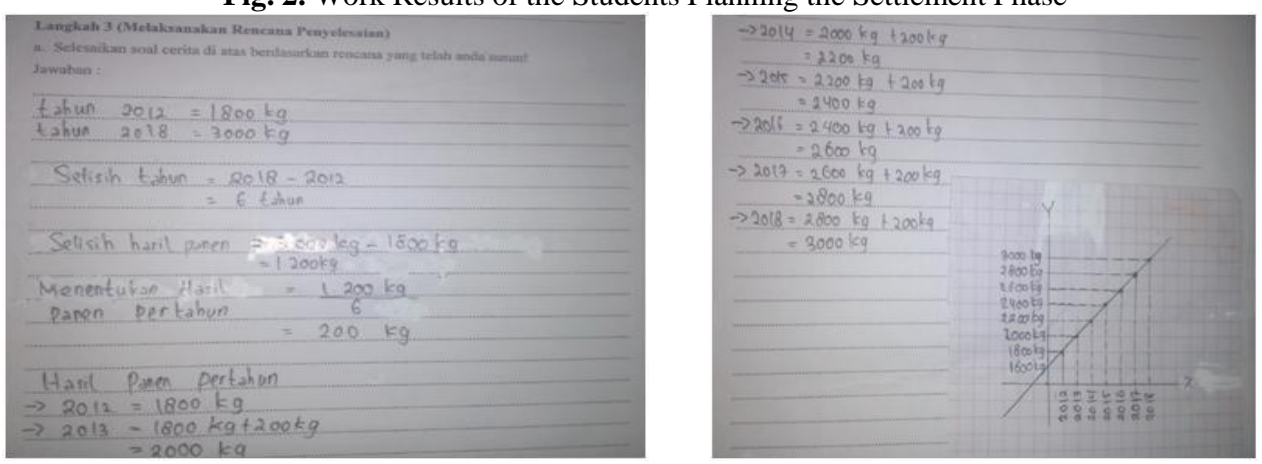
Fig 3. Work Results of Students in the Stage of Implementing the Settlement Plan
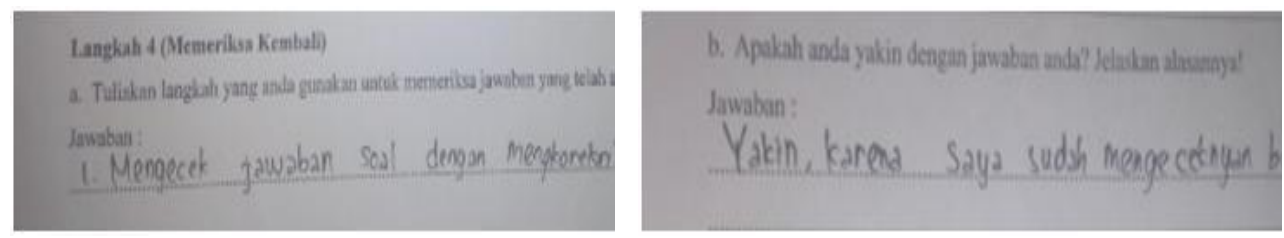

Fig.4. Student Work Results to Re-check the Settlement Phase

Table 2. Interview result

\begin{tabular}{|c|c|c|c|c|c|c|c|c|c|c|}
\hline \multirow{3}{*}{ Subject } & \multirow{3}{*}{$\begin{array}{c}\text { Solve the problem } \\
\text { Polya based }\end{array}$} & \multicolumn{9}{|c|}{ Metacognitive Skills } \\
\hline & & \multicolumn{3}{|c|}{ Planning } & \multicolumn{3}{|c|}{ Monitoring } & \multicolumn{3}{|c|}{ Assessment } \\
\hline & & $P$ & $M$ & E & $P$ & $M$ & E & $P$ & $M$ & E \\
\hline \multirow{4}{*}{ High } & Phase Understanding Problems & $\sqrt{ }$ & $\sqrt{ }$ & $\sqrt{ }$ & & $\sqrt{ }$ & $\sqrt{ }$ & & & $\sqrt{ }$ \\
\hline & Phase Plan for Problem Solving & $\sqrt{ }$ & & $\mathrm{V}$ & $\mathrm{V}$ & $\sqrt{ }$ & $\sqrt{ }$ & & & $\sqrt{ }$ \\
\hline & Phase Implement Problem Solving Plan & $\sqrt{ }$ & $\sqrt{ }$ & $\sqrt{ }$ & $\sqrt{ }$ & $\sqrt{ }$ & $\sqrt{ }$ & $\mathrm{V}$ & $\mathrm{V}$ & $\sqrt{ }$ \\
\hline & Phase Looking Back & $\mathrm{v}$ & & $\mathrm{v}$ & $\mathrm{v}$ & & & $\mathrm{v}$ & & $\mathrm{v}$ \\
\hline
\end{tabular}

\section{Discussion}

Based on the results of observations and interviews, it is known that students in solving problems use their metacognitive skills in each of Polya's steps as follows. At the Phase Understanding Problems, the metacognitive skills used are:

Planning

In the planning stage, students think of ways to understand what is meant in the problem, namely understanding what is known and asked in the question. Students also explain the understanding gained and write it on the answer sheet. In addition, students also re-examine what has been understood through what is known and asked in the question. These activities meet the indicators of planning metacognitive skills in understanding problems.

\section{Monitoring}

At the monitoring stage, Students explain that the concepts used are in accordance with what is asked in the questions relating to the material of straight line equations. Students also check the suitability of the concepts used in solving the problem. Based on the description above, the activities carried out by students meet the indicators of monitoring metacognitive skills in understanding problems. 
Assessment

In the assessment stage armed with concepts that students understand, namely straight-line equations, the subject of students with straight-line graphs is sufficient to determine what is asked in the question. So that activities carried out by students meet indicators of metacognitive skills assessment in understanding problems.

At the Phase Plan for Problem Solving, the metacognitive skills used are:

Planning

At this stage, the Student subject is known in the problem as a help to graph the straight line. From the plan, students are sure that the plan they think is correct. These activities meet the indicators of planning metacognitive skills in planning solutions.

\section{Monitoring}

In the monitoring phase, students think of the steps that will be used in solving the problem. Students also explain the steps that will be used, starting from determining the difference in years, the difference in yields, determining the yield per year then charting the lines in the Cartesian coordinates. The steps that students explain in the interview are also in accordance with what is written in the answer sheet. In addition, students are sure that the steps of the plan used are in accordance with what was asked. So that activities carried out by students meet the indicators of monitoring metacognitive skills in planning solutions.

Assessment

At the assessment stage, students believe the plan used is enough to solve the problem. Students' confidence in the plan used is an indicator of assessment metacognitive skills in planning a solution.

At the Phase Implement Problem Solving Plan, the metacognitive skills used are:

Planning

In the planning stage, students explain the first step taken, namely determining the year difference from 2013 to 2018. In addition, students check again on the questions to make sure the first steps taken are already going well. Students also check the truth of the first step. All activities carried out by students meet the indicators of planning metacognitive skills in implementing the completion plan.

Monitoring

At this stage, students explain the first step taken in solving problems, namely determining the difference between 2013 and 2018 with a difference of 5 years. Students also prevent the possibility of errors in a step. In addition, students examine the suitability of the plan by implementing problem solving so that the coordinates of the points are correct. These activities meet the indicators of monitoring metacognitive skills in implementing the settlement plan.

Assessment

In the assessment phase, students explain the next steps in resolving the problem, because according to students through these steps you can get coordinates to draw a straight line graph. students also monitor the accuracy of each step taken. After scrutiny, students also re-examine the steps used in solving the problem. These activities fulfill the indicators of metacognitive skills assessment in implementing the settlement plan. 
At the Phase Looking Back, the metacognitive skills used are:

Planning

At this stage, students check the suitability of the plan by revisiting from the first step to the last step and adjusting to the concept used. Students also feel that the plan carried out is in accordance with the resolution of the problem. In addition, students are sure the results can be in accordance with the objectives of the problem. Based on the description above, the activities carried out by students meet the indicators of planning metacognitive skills in re-checking.

\section{Monitoring}

In the monitoring phase, students check the calculation in solving the problem. Because according to students, if wrong in calculating the coordinates it will be wrong and the lines are also wrong. The checks carried out by students in the calculation fulfilled the form of indicators of monitoring metacognitive skills in re-checking.

Assessment

At the assessment stage, students check the correctness of the results of the settlement by rechecking the coordinates and adjusting to the concept that has been arranged. Students are also very confident in all the checks done in solving the problem. So that students' confidence in the examination conducted fulfills the form of indicators of assessment metacognitive skills in rechecking.

\section{Conclusion}

Metacognitive skills of high-ability students in solving problems appear in every step of solving Polya-based story problems in detail.

\section{Reference}

[1] A. S. Purnami, S. A. Widodo, and R. C. I. Prahmana, 'The Effect Of Team Accelerated Instruction On Students' Mathematics Achievement And Learning Motivation', in Journal of Physics: Conference Series, 2018, vol. 948, no. 1.

[2] S. A. Widodo, Turmudi, J. A. Dahlan, Istiqomah, and H. Saputro, 'Mathematical Comic Media for Problem Solving Skills', in International Conference on Advance \& Scientific Innovation, 2018, pp. 101-108.

[3] S. Krulik and J. A. Rudnick, 'Innovative Tasks to Improve Critical and Creative Thinking Skills', in Developing Mathematical reasoning in Grades $K-12$, vol. 12, L. V Stiff and F. R. Curcio, Eds. Virginia: The National Council of Teachers of Mathematics, 1999.

[4] Jawa Pos, 'Banyak Logika, Matematika Menjadi Momok Simulasi USBN', Jawa Pos, 2019.

[5] R. Soedjadi, Tips Pendidikan Matematika di Indonesia Keadaan Saat Ini Menuju Harapan Masa Depan. Jakarta: Depdikbud, 2000.

[6] G. Polya, How to Solve It, vol. 30. Princeton University Press, 1973.

[7] U. Sholihah, 'Membangun Metakognisi Siswa dalam Memecahkan Masalah Matematika', Ta'allum J. Pendidik. Islam, vol. 4, no. 1, pp. 83-100, 2018.

[8] S. A. Widodo, R. C. I. Prahmana, A. S. Purnami, and Turmudi, 'Teaching materials of algebraic equation', in Journal of Physics: Conference Series, 2018, vol. 943, no. 1. 
[9] A. L. Wenden, 'Metacognitive Knowledge and Language', Appl. Linguist., vol. 19, no. 4, pp. 515-537, 1998.

[10] J. G. Borkowski, W. Schneider, and M. Pressley, 'The challenges of teaching good information processing to learning disabled students', Int. J. Disabil. Dev. Educ., vol. 36, no. 3, pp. 169-185, 1989.

[11] C. A. Gama, 'Intregrating Metakognition Instruction in Interaktive Learning Environment', University of Susex, 2004.

[12] D. J. Hacker, 'Metacognition : Definitions and Empirical Foundations Flavell's Contribution', in Metacognition in Educational Theory and Practice, D. Hacker, J. Dunlosky, and A. Graesser, Eds. 1998.

[13] J. H. Flavell, 'Metacognition and Cognitive Monitoring: A New Area of CognitiveDevelopmental Inquiry', Am. Psychol., vol. 34, no. 10, pp. 906-911, 1979.

[14] P. Areti and G. Philippou, 'the Measurement of Young Pupils' Metacognitive Ability in Mathematics: the Case of Self-Representation and Self-Evaluation', in Proceedings of CERME, 2005, no. 4, pp. 1-10.

[15] W. Pierce, 'Metacognition: Study Strategies, Monitoring and Motivation', 2003.

[16] J. C. Meniado, 'Metacognitive Reading Strategies, Motivation, and Reading Comprehension Performance of Saudi EFL Students', English Lang. Teach., vol. 9, no. 3, pp. 117-129, 2016.

[17] A. Desoete, 'Off-line metacognition in children with mathematics learning disabilities', 2001.

[18] T. G. Ratumanan and T. Laurent, Penilaian Hasil Belajar Pada Tingkat Satuan Pendidikan. Surabaya: UNESA University Press, 2011. 